\title{
IMPACTO DO PROGRAMA MINHA CASA MINHA VIDA NO DESLOCAMENTO URBANO E NA DEMANDA POR SERVIÇOS PÚBLICOS NO MUNICÍPIO DE SUMARÉ
}

\section{Mariana Fix (PQ), Lívia Toni (IC), Letícia Sousa (IC), Eduardo Maximiliano (IC), William Loures (IC).}

\section{Resumo}

Esta pesquisa teve como objetivo identificar e analisar os impactos do Programa Minha Casa Minha Vida sobre os deslocamentos intra-urbanos e sobre a demanda por serviços públicos de transporte, educação e saúde na cidade de Sumaré, na Região Metropolitana de Campinas. A pesquisa se definiu sobretudo pelo estudo da questão fundiária no Brasil, da implantação do MCMV em outras localidades e da análise do Plano Diretor de Sumaré e de seu histórico habitacional. Foram também aplicados questionários aos moradores dos principais conjuntos habitacionais da cidade: Residencial Emílio Bosco, Residencial Itália e Residencial Jardim das Águas.

Palavras Chave: Minha Casa Minha Vida, Sumaré, Transportes.

\section{Introdução}

Desde que foi lançado em 2009, o Programa Minha Casa Minha Vida (PMCMV) tem adquirido grandes proporções. Como consequência, são vários os impactos a ele associados, entre os quais: a elevação acentuada de preço dos terrenos, a ampliação da mancha urbana, o aumento da demanda por transportes e serviços públicos, a periferização da moradia.

Esta Iniciação Científica está inserida em um projeto de pesquisa do Centro de Estudos de Desenvolvimento Econômico, de avaliação destes impactos, processo no 550717/2012-9, referente à Chamada MCTI/CNPq/MCIDADES № 11/2012.

\section{Resultados e Discussão}

O tempo de deslocamento trabalho-moradia mostrou-se maior em todos os conjuntos, quando comparado ao da moradia anterior. Tal fato evidencia a zona periférica em que os empreendimentos foram implantados. Soma-se ainda a pouca de disponibilidade de ônibus em 2 dos 3 conjuntos.

A demanda por saúde básica (postos de saúde e Unidades de Pronto Atendimento) aumentou muito nas regiões dos empreendimentos, como esperado. Contudo, enfatiza-se a precariedade de tais serviços, que reforça a dependência aos dispositivos de saúde do centro da cidade ou das cidades vizinhas.

Em relação ao acesso à educação, pode-se dizer que sua implantação foi favorável em apenas dois dos conjuntos, onde as unidades de ensino se localizam próximas, ou conta-se com transporte fornecido pelo município. No terceiro constatou-se a falta de vagas e a grande distância até as escolas.

Por fim, contatou-se que a aceitação da mudança foi maior pelas pessoas que deixaram de pagar aluguel em relação àquelas removidas de áreas de risco.

Figura 1. Implementação do PMCMV em Sumaré

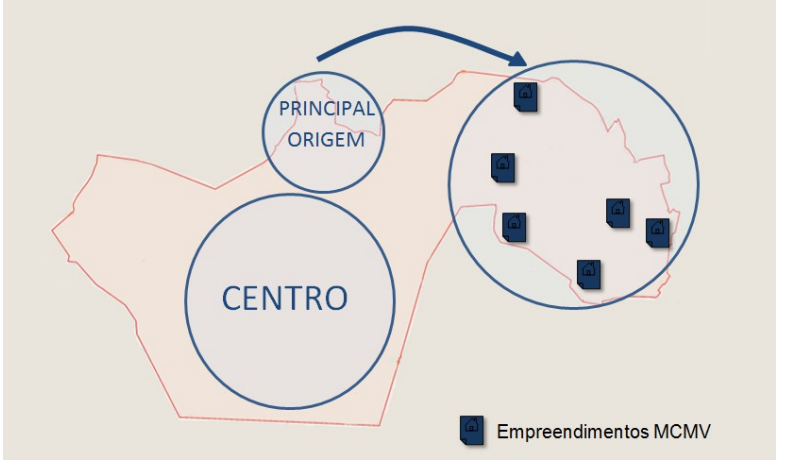

Fonte: elaboração própria.

$$
\text { Conclusões }
$$

A pesquisa mostrou que não houve ampliação da infraestrutura suficiente para atender a demanda trazida pelo PMCMV às regiões dos empreendimentos. Assim, pode-se concluir que sua implementação em Sumaré se deu de forma periférica e insatisfatória.

\section{Agradecimentos}

À Professora Mariana Fix, pelo empenho e dedicação na orientação do projeto. Aos professores e alunos do CEDE, por toda a ajuda. Ao CNPq, pela oportunidade.

\footnotetext{
FIX, Mariana (2011). Financeirização e transformações recentes no circuito imobiliário no Brasil. Tese de doutorado. Campinas: Unicamp.

2 CARDOSO, Adauto (2013). O Programa Minha Casa Minha Vida e seus Efeitos Territoriais. Rio de Janeiro: Letra Capital. ${ }^{3}$ ROLNIK, Raquel (cord.) (2014). Ferramentas para avaliação da inserção urbana dos empreendimentos do MCMV. Relatório de pesquisa. São Paulo: FAU-USP
} 